\title{
DESIGNS ON ENGINEERING
}

\author{
Richard MORRIS and Mark MILNE \\ University of Brighton
}

\begin{abstract}
There has been widespread criticism of the capabilities of engineering graduates produced in the United Kingdom. More than half of employers say that engineering graduate recruits do not reach their expected standards and nearly two thirds think skills gaps are a threat to their business. These failings are identified particularly in the softer rather technical domains including for example design, creativity and communication. A professional body review at the University of Brighton by the engineering professional bodies and in May 2015 also identified these areas as being particularly weak at the University.

From 2016, two University of Brighton academics transitioned from full time lecturing on BSc Product Design programmes to full time lecturing on BEng and MEng programmes. The University was during this period undertaking an institution wide curriculum review and the design academics (the paper authors) used the opportunity to introduce changes to the design provision in the engineering courses. These changes drew on a combined twenty years of design practice, thirty years of design lecturing, and resulted in the application of more design facing pedagogies to the more traditional engineering courses.

This paper outlines the changes that were made and evaluates the outcomes as perceived by final year undergraduate and postgraduate engineering programmes. Whilst it is notoriously difficult to quantify educational effectiveness, the results suggest that engineering students are highly receptive to the design and educational practices that are traditionally separate between design and engineering pedagogy. It is postulated that the rigid and extensive requirements needed to achieve professional body engineering accreditation is actually unhelpful to the creative development of courses needed to produce engineers of the future.
\end{abstract}

Keywords: Engineering pedagogy, project-based learning, holistic teaching

\section{INTRODUCTION}

The United Kingdom industrial base regularly reports a shortage of engineers. It is estimated that there are only half as many graduates as employees need [1] with a predicted recruit shortage of 257,000 engineers [2]. The irony is that the engineering sector within UK Higher Education looks to be well served with over one hundred and thirty-five academic institutions providing mechanical and electrically based degree qualifications. One of the issues for employers is the quality of graduates and more than half of UK employers say that engineering graduates do not reach their expected standards [3]. Failings are identified particularly in the softer rather technical domains including for example practical working skills, design, creativity and communication [3, 4]. In addition to the more widespread national weaknesses in engineering graduates, a professional body review of engineering at the University of Brighton in May 2015 also identified these areas as being weak at the University. It is imperative that engineering courses change and address these softer areas. Nearly two thirds of companies think these skills gaps are a threat to their business [3] whilst university's themselves face increasing pressure from competition including overseas courses, on line education and an increasing number of alternative routes to engineering including apprenticeships and $\mathrm{T}$ qualifications. The Royal Academy of Engineering consider not why universities should change, but when and how [5].

\section{IMPLEMENTING CHANGE}

From 2016, two University of Brighton academics transitioned from full time lecturing on BSc Product Design programmes to full time lecturing on BEng/MEng programmes. The design academics (and paper authors) implemented a review of design in the engineering courses as part of an institution 
wide curriculum review. The academics evaluated and summarised the different approaches to teaching design in Engineering and in Product Design at Brighton are shown in Table 1:

Table 1. Engineering and Design Pedagogies

\begin{tabular}{|l|c|c|}
\hline & Engineering & Product Design \\
\hline 1. Aims & Knowledge based & Cognitive based \\
\hline 2. Pedagogy & Instructive, theoretical, tutor led, & Action learning, practical, student led \\
\hline 3. Approach & Scaffolded (new topics each year) & Holistic (adding depth each year) \\
\hline 4. Themes & technical, common projects & real world, social, individual projects \\
\hline 5. Content & Technical & Process \\
\hline 6. Organisation & 6 modules per week & 1 module per week \\
\hline 7. Lectures & Slide based lectures & Exercise based \\
\hline 8. Tutorials & Registered, compulsory, assessed & Voluntary \\
\hline 9. Group working & Large, course based & Small, mixed \\
\hline 10. Assessment & Report, exam, prescriptive & Portfolio, evaluative \\
\hline
\end{tabular}

It is suggested that these approaches were typical not just in the way design was taught differently in the two disciplines at Brighton, but typical of the generic pedagogic approaches in the different domains of Product Design and Engineering across higher education. Changes were consequently made to design teaching. At lower levels more, emphasis was put on holistic and basic design practice, increasing sketching, communication and group skills and management content moved to higher levels. More design facing pedagogies were implemented in the final; smaller groups working on more real-world individual projects, more evaluative learning outcomes assessed through video media rather than reports, less emphasis on the technical and more emphasis on the creation and the process, more exercise-based learning with tutorials rather than slides. These changes were implemented across one hundred and twenty final year engineering students in 2017/18 and eighty final year mechanical and electrical engineering students in 2018/19. Twenty-eight postgraduate students who had moved through the changes in 2017/18 then progressed onto a new, higher level advanced design module in 2018/19 which included more challenging 'wicked' problems, a more discursive pedagogy, deeper and more sophisticated design techniques and content, and more peer to peer learning through Action Learning sets as opposed to the more traditional tutorials.

Educational developments are notoriously difficult to evaluate, often requiring longitudinal studies revolving around a combination of student and programme performance, and/or institutional and stakeholder metrics [6]. The method adopted here was to evaluate the student experience over a twoyear period by commenting anonymously on the outcomes of their studies via a questionnaire using quantitative Likert scales and qualitative free text boxes. The questions are shown below:

1. Most modules were changed from year-long delivery to delivery in a single semester, reducing the number of subject's studies per week from five or six, to two or three. Has this change helped and improved your study experience?

2. Some 'management' and 'innovation' topics were moved to level 7 to enable more focus at level 6 on understanding the basic design process and developing practical design skills. The Level 6 module title was changed to reflect this, from 'Product Innovation and Management' to 'Product Design'. Was this change beneficial and helped to improve your understanding of design?

3. Teaching and Learning methods were changed from tutor led instruction to more student led 'learning by doing'. Do you find this a better method to learn or not?

4. The module was delivered in a way that stepped through the design process week by week. Did this approach help your studies and understanding of the design process?

5. Project themes were changed from 'gadget' to 'social issues'. Did this challenge enhance your learning and study experience?

6. The manufacturing and technical content of the module was decreased and softer skills such as design, creativity, sketching and modelling were increased. Do you value these changes?

7. Lectures attempted to move away from solely slide based presentations to include in class exercises. Does this method improve your learning?

8. Tutorials were changed from being compulsory, registered and assessed to voluntary attendance. Is this a better approach? 
9. Group sizes were reduced from 10 to 5. Did this improve your study experience?

10. Assessment was changed from a prescriptive report to an evaluative video. Do you value this alternative approach in thinking and method?

11. The module aims to develop the basic design skills learnt at Level 6 to a deeper level with more challenging problems and innovative solutions. Has this been successful?

12. Lectures have developed from slides and exercises at level 6 to include more discursive elements. Has this approach improved your learning and study experience?

13. The module content had aimed to introduce more sophisticated techniques and practices. Has this been successful?

14. Tutorials have developed from tutor led sessions to peer led Action Learning Sets. Has this improved your learning and study experience?

\section{RESULTS}

There were forty-seven undergraduate and fourteen postgrads student responses. A summary of the results is given in order of student preference:

1. $87 \%$ unsurprisingly preferred the reduction to smaller group sizes. What was surprising, given that most students do not like group working, was the acknowledgement by the M.Eng. level students that they would have preferred to continue group working in their design studies at postgraduate level (Q 9.) The key seemed to be the acknowledgement that working on hard problems requiring many creative ideas benefitted from a team-based effort.

2. $85 \%$ of students responded positively to the reduction of modules from six per semester to three. Forty-four offered positive comments, and only two were lukewarm (Q 1.). The predominant aspect of comments received was the time this allowed to focus on subjects rather than being spread across so many topics, and how this provided a more relaxing, healthier and enjoyable learning experience.

3. $83 \%$ approved of the weekly step by step approach to the subject matter which they reported as providing context and helping them organise and understand the topics and the process $(\mathrm{Q} 4$.)

4. $70 \%$ approved of the practical, learning by doing and student led approach. Only $4 \%$ lamented the reduction in the slide-based approach, citing the increase in confusion that could take place without tutor guidance. (Q 3.)

5. $70 \%$ though the attempt to move away from slide-based lectures was good, but with $30 \%$ largely indifferent. Comments from the indifferent answers suggested that there was not enough difference, and that the changes needed to be more profound with even fewer lectures $(\mathrm{Q} 7$.

6. $62 \%$ considered it good to move the management topics to a higher level so that design could be the main focus. $26 \%$ were indifferent and $7 \%$ were not in favour (Q 2.)

7. $61 \%$ thought the inclusion of softer design and communication skills was a better or much better course change. $16 \%$ thought it was not a good change commenting that these were skills they think they could pick up elsewhere and would have preferred more technical knowledge that they felt was covered weakly elsewhere (Q 6.) They liked, valued and wanted the extra design skills but they want the technical skills as well and not instead of.

8. $57 \%$ liked the change to an evaluative video assessment format. $32 \%$ were indifferent and $11 \%$ thought it worse (Q 10.). It had been felt that students would like the video format, but in fact this was polarising with many liking the innovation, challenging, engaging and industrial/real world nature, and noting they were sick of writing reports, but others found the video needed more effort and skills that they were unlikely to use again and were more suspicious of their ability to supply nuances and detail.

9. 53\% liked the step change from component and 'gadget' projects to more challenging real-world problems. $41 \%$ were indifferent and $6 \%$ saw no benefit at all (Q 5.) This might again suggest some scope to reinforce the scale of challenges to be tackled.

10. Only $37 \%$ of students liked the more responsible voluntary approach to tutorials, with $15 \%$ considering it to be not a good change (Q 8.). (It was however noted by tutor records that attendance at the tutorials was exceptionally high).

For the postgraduate engineering students: 
11. $100 \%$ felt that that the 'holistic' approach was good, i.e. studying a complete design understanding at level 6 but expanding on this at level 7 as opposed to studying some topics at level 6 and others at level 7 (Q 11.)

12. $92 \%$ agreed that the study of design had progressed to a more sophisticated level (Q 13.)

13. $84 \%$ approved strongly of the discursive approach to design at level 7 rather than a slide or even exercise-based approaches (Q 12.)

14. $69 \%$ liked the Action Learning Sets. $31 \%$ were indifferent. It is suggested by the tutors that students were initially sceptical of the ALS, and sceptical of the benefits of peer feedback as opposed to tutor feedback, and accordingly some 'gave up' early on. Those who persisted however came to appreciate their value with some significance.

\section{CONCLUSIONS}

Anybody wishing to implement similar course changes within engineering might consider more design-based pedagogies. If they were hoping to draw from this study, they might choose to ignore the less important changes in this study, including the nature of a project for example although it is noted that this stands in contrast to some other studies including those reported at previous. Engineering and Product Design Engineering conferences (EPDE) which suggest the nature of the challenge is important. Inevitably context is important, and there may be the scope to improve the delivery and implementation of the changes. No matter how well intentioned any changes are, each change has to be well thought out, well implemented, and well supported. The attitude towards tutorial attendance and the assessment formats were also surprisingly noted by students as being less important to them.

Course teams might instead more simply note the more well received changes in this study; Smaller groups where group working is required, or more project based and thought our delivery schedule that places all subjects for the week in some kind of context as noted in other design studies [7]. Fewer modules per week was also extremely popular. The normal university modular format with typically five or six modules studied per week for example might provide 'subject choice' but lumbers students with complex organisation with shallower focus and immersion in specific subjects. Students highly praised the reduction in modules, which is much more common in design-based teaching. Better 'focus' was cited in $50 \%$ of student responses, alongside comments on easier organisation, less stress, and better enjoyment.

If the popularity of these changes isn't surprising, noted often in design studies but less so in engineering, why is that more change is not forthcoming? It seems surprising for example that the multiple delivery modular system, which has become endemic in education since its evolution from the 1960s, is still dominant. One reason might be tradition; engineering courses have a longer history than that of design. Another might be that design is a more mixed bag of subjects requiring a more open attitude to pedagogic practice. Another might be class sizes with larger engineering classes offering a barrier to change. Another barrier for change might be restrictions arising from the professional oversight of engineering.

\section{FURTHER DEBATE}

The Finniston Report led to the abolition of the Council of Engineering Institutions oversight body and the creation of the Engineering Council (EC) [8]. One of the aims of the EC was to reduce the variability of the engineering courses, and it now has a requirement for courses to meet thirty-six criteria in order to become accredited and allow its graduates to have a professional body recognition. Whilst this has reduced course variability, has the requirement to meet so many criteria stifled flavour and innovation within engineering degrees? Professional course accreditation is viewed as mandatory by institutions and the design of courses is subject to review, and thus the institutions carry significant power in the outcome of course design. There are multiple stakeholders, society, industry, students and academic institutions, all relying on the accrediting bodies ensuring that all these needs are reflected in the decision-making process. It is suggested the benefits of success are engaged, motivated successful students, understanding and meeting societal needs and those of the industries they decide to enter. The Hamilton Review of Engineering is clear; "one cannot help feeling that the present arrangements [for accreditation] are unnecessarily complex, burdensome for the universities and subject to inconsistencies" [9]. In other words, is the quality tail now wagging the student experience dog? Designers and design educators will know that quality can inhibit innovation, and there is much research evidence within education to support this too. As Peter Williams, former chief executive of 
the UK Quality Assurance Agency puts it; "The "dead hand of uniformity" is being promoted by higher education accreditation systems" [10]. The authors believe it is so too, having seen the design changes evolve whilst engineering has not, and having now seen the positive results from some Design based changes being made in Engineering. They respectfully suggest that it is time for the Engineering Council to encourage and enable engineering courses to achieve flexibility, progression and innovation in order to achieve much needed change and suggest renewed debate between all parties concerned.

\section{REFERENCES}

[1] Kumar A. et al. The State of Engineering 2016, 2016, Engineering UK.

[2] Knowles E. (Ed). Overview of the engineering and manufacturing sector in the UK, 2016, Prospects.

[3] Institute of Engineering and Technology. Skills and Demand in Industry Survey 2015, 2015, Institution of Engineering and Technology.

[4] Wakeham W. STEM Degree Provision and Graduate Employability, 2016, UK Government Department of Business, Innovation and Skills \& the Higher Education Funding Council for England.

[5] Graham R. Achieving Excellence in Engineering Education; the ingredients of successful change, 2012, The Royal Academy of Engineering \& Massachusetts Institute of Technology

[6] Wilkes M. Evaluating Educational Interventions, 1999, British Medical Journal.

[7] Dekininck E. Enhancing the Innovation Skills in Engineering Students, 2012, International Conference on Engineering and Product Design Education, Antwerp, Belgium.

[8] Finniston M. The Report of the Committee of Inquiry into the Engineering Profession, 1980, HM Government Department of Trade and Industry.

[9] Hamilton Sir J. The Engineering Profession, 2000. Engineering Council.

[10] Williams P. Worlds Innovation Summit for Education. 2009. 